Case report

\title{
Successful Weight Reduction in Metabolic Syndrome with a Hypocaloric Plant-Based Diet (Lacto-ovo-vegetarian Diet) with Exercise During an Educational Hospitalization: Report of Three Cases
}

\author{
Mitsuro Chiba ${ }^{1,}{ }^{*}$, Masafumi Komatsu ${ }^{1}$, Satomi Watanabe ${ }^{2}$, Yoko Daimon ${ }^{3}$
}

1. Division of Gastroenterology, Akita City Hospital, 4-30 Matsuoka-machi, Kawamoto, Akita City 010-0933, Japan; E-Mails: mchiba@m2.gyao.ne.jp; ac990892@akita-city-hp.jp

2. Clinical Laboratory, Akita City Hospital, 4-30 Matsuoka-machi, Kawamoto, Akita City 010-0933, Japan; E-Mail: ac910805@akita-city-hospital.jp

3. Division of Radiology, Nakadori General Hospital, 3-15 Misono-cho, Minami-Dori, Akita City 0108577, Japan; E-Mail: y.daimon001@email.com

* Correspondence: Mitsuro Chiba; E-mail: mchiba@m2.gyao.ne.jp

Academic Editors: Roberto Cannataro, Diego A. Bonilla and Jorge Luis Petro Soto

Special Issue: Nutrition and Exercise for Weight loss

OBM Integrative and Complementary Medicine

2021, volume 6 , issue 1

doi:10.21926/obm.icm.2101006
Received: January 13, 2021

Accepted: February 12, 2021

Published: February 20, 2021

\begin{abstract}
The high prevalence of obesity is a global concern. However, obesity and inflammatory bowel disease have similarities in epidemiology, diet, and gut microbial dysbiosis. An omnivorous (westernized) diet replacement with a plant-based diet in inflammatory bowel disease achieved better outcomes in both the induction and quiescent phases. Educational hospitalization providing a plant-based diet was found effective in suppressing flare-up in ulcerative colitis. This case report was designed to assess whether a plant-based diet can reduce body weight in patients with obesity during educational hospitalization for a short period of two weeks. Three men with metabolic syndrome $(55,61$, and 65 years old) were included in the study with body mass index ranging from 27.0 to $31.2 \mathrm{~kg} / \mathrm{m}^{2}$ and visceral fat area between 94.7 and $128 \mathrm{~cm}^{2}$. In Japan, a body mass index of $\geq 25$ is defined as obesity. A lacto-ovo-vegetarian diet with brown rice (1400 or $1100 \mathrm{kcal} /$ day), a plant-based diet, was
\end{abstract}

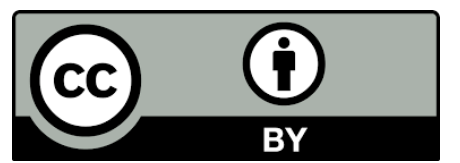

(C) 2021 by the author. This is an open access article distributed under the conditions of the Creative Commons by Attribution License, which permits unrestricted use, distribution, and reproduction in any medium or format, provided the original work is correctly cited. 
provided during hospitalization for around two weeks. Patients walked for about $1 \mathrm{~h}$ in a park daily during the hospitalization. All three patients showed weight loss: $2.9 \%, 6.1 \%$, and $6.6 \%$ at discharge. A decrease in body mass index, waist circumference, and the visceral fat area was also observed. Restriction in total calories in the form of a plant-based diet and daily 1hour walks through an educational hospitalization for two weeks effectively reduced body weight and improved obesity-related parameters. Thus, a plant-based diet could be an effective weight-loss diet.

\section{Keywords}

Metabolic syndrome; vegetarian diet; obesity; plant-based diet; educational hospitalization; weight-loss diet; environmental factor; dietary transition; gut microbiota

\section{Introduction}

The high incidence of diet-related obesity and chronic diseases, including coronary heart disease, stroke, and diabetes mellitus, has raised global health concerns [1]. In the USA during the last 70 years (between 1910 and 1980), the ratio of fat and carbohydrates to total energy intake gradually increased from $33 \%$ to $43 \%$ and decreased from $55 \%$ to $46 \%$, respectively. The protein ratio increased only $1 \%$, from $12 \%$ to $13 \%$ [2]. There seems to be a gradual dietary transition from the traditional diet to dietary westernization. In other western countries, a dramatic dietary transition to a westernized diet occurred after the Second World War [3]. Typical dietary transitions are associated with the socio-economic transition. However, food industries that produce foods rich in fats at low cost and urbanization induced similar westernization in low-income countries. Popkin pointed out a global dietary transition from a traditional to a westernized diet in Asia, South America, and Africa between 1962 and 1994 and warned that such a transition was destined to increase dietrelated obesity and chronic diseases [4, 5], which became a reality. In Japan, the criterion for obesity is a body mass index $(\mathrm{BMI}) \geq 25 \mathrm{~kg} / \mathrm{m}^{2}$ instead of $\geq 30 \mathrm{~kg} / \mathrm{m}^{2}[6]$. Obesity $\left(\mathrm{BMI} \geq 25 \mathrm{~kg} / \mathrm{m}^{2}\right)$ constitutes around one-third of adult men (33.0\%) and one-fifth of adult women (22.3\%) in Japan, according to the National Study in 2019 [7]. There is an excess of current global consumption of unhealthy foods such as red meat, sugar, refined grains, and a shortage of healthy foods such as vegetables, fruits, legumes, whole grains, and nuts [1]. Recently, research on the interplay between diet, gut microbiota, microbial metabolites, and health/disease showed that current omnivorous (westernized) diets characterized by high animal fat with less dietary fiber were pro-inflammatory. In contrast, traditional diets like plant-based diet (PBD) characterized by low animal fat and high dietary fiber were anti-inflammatory $[8,9]$. This suggests that the current omnivorous (westernized) diet is problematic.

Inflammatory bowel disease (IBD), a collective term for ulcerative colitis (UC) and Crohn's disease (CD), affects the younger generation with a peak age between 15 and 25 years. The incidence of IBD has increased over time, expanding to different regions worldwide, indicating a global disease [10]. The epidemiology of IBD is quite similar to obesity. Increased incidence of inflammatory bowel disease associated with the dietary transition (westernization) was found in Japan (Chiba $\mathrm{M}$ et al.). 
Although IBD etiology is unknown, like other diseases, IBD is accepted as a multi-factorial disease occurring in susceptible persons (genetic factors) triggered by environmental factors [10]. Although there is no widely accepted key environmental factor, a westernized diet is considered the most ubiquitous environmental factor underlying IBD due to several reasons described previously [11, 12]. Thus, IBD is a lifestyle disease mainly mediated by a westernized diet. Consequently, a lactoovosemi-vegetarian diet, a PBD, was developed to counter a westernized diet. A traditional lowresidue diet or omnivorous (westernized) diet was replaced with PBD for in patients with IBD in 2003 [11]. Although our studies were uncontrolled with a small sample size, we achieved better induction and relapse rates in CD and UC than the current standard treatment by incorporating the PBD [13]. Based on our experience with the PBD for IBD and the pathogenesis of IBD, we recommend PBD for IBD [13]. Diet is involved in both obesity and IBD. Gut microbial dysbiosis is observed in both obesity and IBD [14, 15], which results in an increased oxidative stress metabolism and a decreased butylate production [14, 16]. They act as pro-inflammatory [8, 9]. If PBD is effective for IBD, it could be effective for weight loss in obesity. In fact, PBD was effective in both UC and nonalcoholic fatty liver disease (NAFLD) in our patient with established NAFLD, in whom UC was newly developed [17]. In the case report, 3.5\% of weight loss was observed during educational hospitalization of 11 days [17].

Here, we report three cases with metabolic syndrome aimed at weight loss with PBD during educational hospitalization.

\section{Material and Methods}

\subsection{Inclusion in Educational Hospitalization Aimed at Weight Loss in Obesity Disease}

Patients with obesity who wanted to lose weight despite their previous effort were included.

\subsection{Educational Hospitalization for Obesity Disease}

Patients scheduled for educational hospitalization were provided with a questionnaire of dietary habits and lifestyle behavior. The questionnaire included 45 questions of food-frequency covering almost all foods or food groups in Japan [11]. The completed questionnaire was obtained immediately after admission, before providing information about the PBD. A chart was created based on the questionnaire that summarized a patient's current and future recommended lifestyle and dietary habits [11]. The recommended dietary habits in the chart were consistent with the PBD. This chart was given to the patient during hospitalization and was used by the dietitian when providing dietary guidance.

PBD was provided as mentioned below. Patients were encouraged to walk for about $1 \mathrm{~h}$ in a park daily during hospitalization. Patients were provided with educational material on lifestyle diseases, healthy lifestyle habits [18], and information on PBD. Patients were provided with answers to any query. A registered dietitian also visited the patients, talked to them about the PBD, and helped them get used to it. At the end of the hospitalization, a qualified dietitian gave the patients and the person who prepared the patients' meals dietary guidance with a PBD guide [11]. Laboratory tests, including any previous abnormal laboratory tests, were repeated. Patients were advised to continue with the PBD even after discharge. 


\subsection{Plant-Based Diet}

\subsubsection{Plant-Based Diet (PBD)}

PBD comprised a lacto-ovo-vegetarian diet (about 1400 or $1100 \mathrm{kcal} /$ day) with fish once a week and meat once every two weeks [11]. White rice was served first for two days, followed by mixed rice (70\% white rice and $30 \%$ unrefined whole brown rice) for two days, and finally served brown rice. Patients were provided with 4-week different menus on a rotational basis. The protein, fat, and carbohydrate rates in total calories were $16.1 \pm 0.5 \%, 18.6 \pm 1.4 \%$, and $66.1 \pm 1.6 \%$, respectively. The rate of fat in total calories (18.6\%) was lower than $20 \%$, which is the lower limit in Dietary Reference Intake for Japanese [19]. PBD contained $32.4 \pm 2.1 \mathrm{~g}$ of dietary fiber $/ 2,000 \mathrm{kcal}$ (soluble dietary fiber $6.8 \pm 0.7 \mathrm{~g}$, and insoluble dietary fiber $23.3 \pm 1.6 \mathrm{~g}$ ) [11]. Saturated fat was $2.9 \%$ of the total calories, dietary cholesterol was $144.4 \mathrm{mg} / 1400 \mathrm{kcal}$, and polyunsaturated/saturated fatty acids was 2.1 [11]. Details of the contents of nutritional elements, including minerals, vitamins, and fatty acids in the PBD, were reported previously [11]. Coarse tea was served along with the meal service. Foods other than the meal service were discouraged.

\subsubsection{Plant-Based Diet Score (PBDS)}

A PBDS was calculated based on the questionnaire for Japanese patients with IBD. The method for PBDS calculation was described previously [20]. Briefly, eight items considered to be preventive factors for IBD had a positive score, and eight items considered IBD risk factors had a negative score. The PBDS was calculated as the sum of the positive and negative scores. A higher PBDS indicated greater adherence to PBD. The PBDS of PBD during hospitalization was 35 [20].

\subsection{Evaluation of Efficacy}

Weight loss at the end of the hospitalization was the primary goal. Secondary endpoints included improvement in obesity-related parameters: BMI, waist circumference, visceral fat area (VFA) and subcutaneous fat area (SFA), blood pressure, fasted blood sugar, hemoglobin A1c, triglyceride, highdensity lipoprotein (HDL) cholesterol, low-density lipoprotein (LDL) cholesterol, total cholesterol, uric acid, aspartate aminotransferase (AST), alanine aminotransferase (ALT), and $\gamma$-glutamyl transpeptidase ( $\gamma$-GTP). VFA and SFA were examined by abdominal computed tomography (CT) or the dual impedance method (Dualscan HDS-200, Omron Colin Ltd., Tokyo, Japan).

\subsection{Follow up Study}

Patients were followed-up till they visited our division.

The study conformed to the ethical principles laid out in the 1975 Declaration of Helsinki. Mitsuro Chiba obtained written informed consent from all subjects.

\section{Results}

Only three patients with obesity visited our division to lose weight. All three patients fulfilled the Japanese diagnostic criteria for metabolic syndrome [21]. Demographic and obesity-related diseases in the three cases are presented in Table 1. Anthropometry, obesity-related parameters, 
OBM Integrative and Complementary Medicine 2021; 6(1), doi:10.21926/obm.icm.2101006

and other findings at baseline and the end of educational hospitalization are shown in Table 1. PBDS of 3 cases before the educational hospitalization and hospital meals is presented in Table 2 . 
OBM Integrative and Complementary Medicine 2021; 6(1), doi:10.21926/obm.icm.2101006

Table 1 Demographics of three patients with metabolic syndrome.

\begin{tabular}{|c|c|c|c|c|c|c|}
\hline & \multicolumn{2}{|l|}{ Case 1} & \multicolumn{2}{|l|}{ Case 2} & \multicolumn{2}{|l|}{ Case 3} \\
\hline Sex/Age & \multicolumn{2}{|l|}{ Male 65} & \multicolumn{2}{|l|}{ Male 61} & \multicolumn{2}{|l|}{ Male 55} \\
\hline Past history and associated disease & \multicolumn{2}{|c|}{$\begin{array}{l}\text { Colonic diverticulitis at } 51 \text { yo } \\
\text { Prostate hypertrophy }\end{array}$} & \multicolumn{2}{|c|}{$\begin{array}{l}\text { Prostate cancer at } 56 \text { yo } \\
\text { Hypertension at } 60 \text { yo }\end{array}$} & \multicolumn{2}{|c|}{$\begin{array}{l}\text { Cholecystectomy at } 48 \text { yo } \\
\text { Hypertension \& dyslipidemia at } 51 \text { yo }\end{array}$} \\
\hline \multicolumn{6}{|l|}{ (Unit) Reference } & On discharge \\
\hline Height (cm) & 164.0 & n.a. & 158.5 & n.a. & 172 & n.a. \\
\hline Weight (kg) & 80.0 & 75.1 & 78.4 & 73.2 & 79.8 & 77.5 \\
\hline BMI $\left(\mathrm{kg} / \mathrm{m}^{2}\right)(18.5-<25.0)$ & 29.7 & 27.9 & 31.2 & 29.1 & 27.0 & 26.2 \\
\hline Waist $(\mathrm{cm})$ male $<85$ & 96.0 & 92.0 & 104.0 & 97.8 & 93.0 & 91.0 \\
\hline Visceral fat area $\left(\mathrm{cm}^{2}\right)<100$ & 97.0 & 90.3 & 94.7 & 77.0 & 128 & 103 \\
\hline Subcutaneous fat area $\left(\mathrm{cm}^{2}\right)$ & 202.4 & 177.4 & 222.2 & 174.4 & n.a. & n.a. \\
\hline \multicolumn{7}{|l|}{ Blood pressure (mmHg) } \\
\hline Systolic $<130$ & 130 & 140 & 164 & 130 & 120 & n.t. \\
\hline Diastolic $<85$ & 86 & 82 & 70 & 70 & 82 & n.t. \\
\hline Fasting blood sugar $(\mathrm{mg} / \mathrm{dl})<110$ & 130 & 83 & 111 & 105 & 102 & n.t. \\
\hline Hemoglobin A1c (\%) 4.3-5.8 & 5.3 & n.t. & 4.9 & n.t. & 5.4 & n.t. \\
\hline Triglyceride $(\mathrm{mg} / \mathrm{dl})<150$ & 122 & 104 & 90 & 66 & 108 & 71 \\
\hline $\mathrm{HDL}-\mathrm{C}(\mathrm{mg} / \mathrm{dl}) 40<$ & 56 & n.t. & 52 & 50 & 60.0 & 43 \\
\hline
\end{tabular}


OBM Integrative and Complementary Medicine 2021; 6(1), doi:10.21926/obm.icm.2101006

\begin{tabular}{|c|c|c|c|c|c|c|}
\hline LDL-C (mg/dl) 70-139 & n.t. & n.t. & 121 & 107 & 119 & 136 \\
\hline Total cholesterol (mg/dl) 110-220 & 213 & 229 & 190 & 172 & 260 & 193 \\
\hline Uric acid (mg/dl) m 3.6-7.0 & 9.2 & n.t. & 4.4 & 4.2 & n.t. & n.t. \\
\hline Fatty liver by ultrasonography & + & n.t. & - & n.t. & + & n.t. \\
\hline AST (U/L) 13-33 & 54 & 67 & 19 & n.t. & 14 & n.t. \\
\hline $\operatorname{ALT}(U / L) m ~ 8-42$ & 76 & 119 & 19 & n.t. & 18 & 20 \\
\hline v-GTP (U/L) 10-47 & 173 & 108 & 20 & n.t. & 38 & n.t. \\
\hline Smoking & - & - & - & - & - & - \\
\hline Daily alcohol drinking & + & - & + & - & + & - \\
\hline Metabolic risk [22] & Moderate & & Mod & & Moc & \\
\hline
\end{tabular}

BMI, body mass index; AST, aspartate aminotransferase; ALT, alanine aminotransferase; $\gamma$-GTP, $\gamma$-glutamyl transpeptidase

n.a.; noa available; n.t., not tested

Table 2 Plant-based diet score (PBDS) for Japanese patients with inflammatory bowel disease.

\begin{tabular}{|c|c|c|c|c|c|c|c|c|}
\hline \multirow[t]{2}{*}{ Food group } & \multicolumn{4}{|c|}{ Scoring by frequency of consumption } & \multicolumn{3}{|c|}{ Measured PBDS before hospitalization } & \multirow[t]{2}{*}{$\begin{array}{l}\text { PBDS during hospitali- } \\
\text { zation }\end{array}$} \\
\hline & Daily & $\begin{array}{l}\text { 3-5 servings } \\
\text { /wk }\end{array}$ & $\begin{array}{l}1-2 \text { servings } \\
\text { /wk }\end{array}$ & Rarely & Case 1 & Case 2 & Case 3 & \\
\hline Vegetables & 5 & 3 & 1 & 0 & 5 & 5 & 3 & 5 \\
\hline Fruits & 5 & 3 & 1 & 0 & 5 & 1 & 3 & 5 \\
\hline $\begin{array}{l}\text { Pulses (beans, soybeans, peas, } \\
\text { etc) }\end{array}$ & 5 & 3 & 1 & 0 & 5 & 3 & 3 & 5 \\
\hline Potatoes/starches & 5 & 3 & 1 & 0 & 1 & 1 & 1 & 5 \\
\hline
\end{tabular}


OBM Integrative and Complementary Medicine 2021; 6(1), doi:10.21926/obm.icm.2101006

\begin{tabular}{|c|c|c|c|c|c|c|c|c|}
\hline Rice & 5 & 3 & 1 & 0 & 5 & 3 & 5 & 5 \\
\hline Miso soup & 5 & 3 & 1 & 0 & 5 & 5 & 5 & 5 \\
\hline Green tea & 5 & 3 & 1 & 0 & 0 & 5 & 1 & $5 *$ \\
\hline Yoghurt (plain) & 5 & 3 & 1 & 0 & 0 & 0 & 0 & 0 \\
\hline Meat (beef, pork, chicken) & -5 & -3 & -1 & 0 & -1 & -1 & -3 & 0 \\
\hline Minced or processed meat & -5 & -3 & -1 & 0 & 0 & -1 & -1 & 0 \\
\hline Cheese/butter/margarine & -5 & -3 & -1 & 0 & 0 & 0 & -1 & 0 \\
\hline Sweets/ice cream/milk shake & -5 & -3 & -1 & 0 & -3 & -1 & -3 & 0 \\
\hline $\begin{array}{l}\text { Soft drinks (cola/carbonated } \\
\text { beverages/juice) }\end{array}$ & -5 & -3 & -1 & 0 & -1 & -1 & -3 & 0 \\
\hline Alcohol & -5 & -3 & -1 & 0 & -5 & -5 & -5 & 0 \\
\hline Bread & -5 & -3 & -1 & 0 & -1 & -1 & -3 & 0 \\
\hline Fish & -2 & -1 & 0 & 0 & -2 & -1 & -2 & 0 \\
\hline Plant-based diet score (PBDS) & & & & & 13 & 12 & 0 & 35 \\
\hline
\end{tabular}

*Green tea is recommended to drink at home but is not provided at the hospital 


\subsection{Case 1}

A 65-year-old man, head of a construction company, underwent health screening at our hospital in early May 2006 and was diagnosed with metabolic syndrome. He suffered a lumbar disk hernia at the age of 40 and was taking medication for prostate hypertrophy.

His initial height, body weight, and BMI were $164.0 \mathrm{~cm}, 79.1 \mathrm{~kg}$, and $29.4 \mathrm{~kg} / \mathrm{m}^{2}$, respectively (Figure 1). Waist circumference was $96.0 \mathrm{~cm}$, fasting blood sugar was $127 \mathrm{mg} / \mathrm{dL}$, and blood pressure was 116/89 $\mathrm{mmHg}$ (Figure 1). These parameters fulfilled the Japanese diagnostic criteria for metabolic syndrome [21]. Other obesity-related diseases detected at the health screening were hypercholesterolemia $(252 \mathrm{mg} / \mathrm{dL})$ and hyperuricemia $(9.2 \mathrm{mg} / \mathrm{dL})$ [6]. Liver function tests were abnormal (AST $89 \mathrm{U} / \mathrm{I}$, ALT $91 \mathrm{U} / \mathrm{I}$, and $\mathrm{y}$-GTP $140 \mathrm{U} / \mathrm{I}$ ) (Figure 1). Since 1984 (43-year-old), his body weight has ranged from 75 to $77 \mathrm{~kg}$. His prior efforts to reduce body weight were in vain. Therefore, he wanted to lose weight by undergoing educational hospitalization for a short period of about two weeks and was admitted in mid-July 2006.

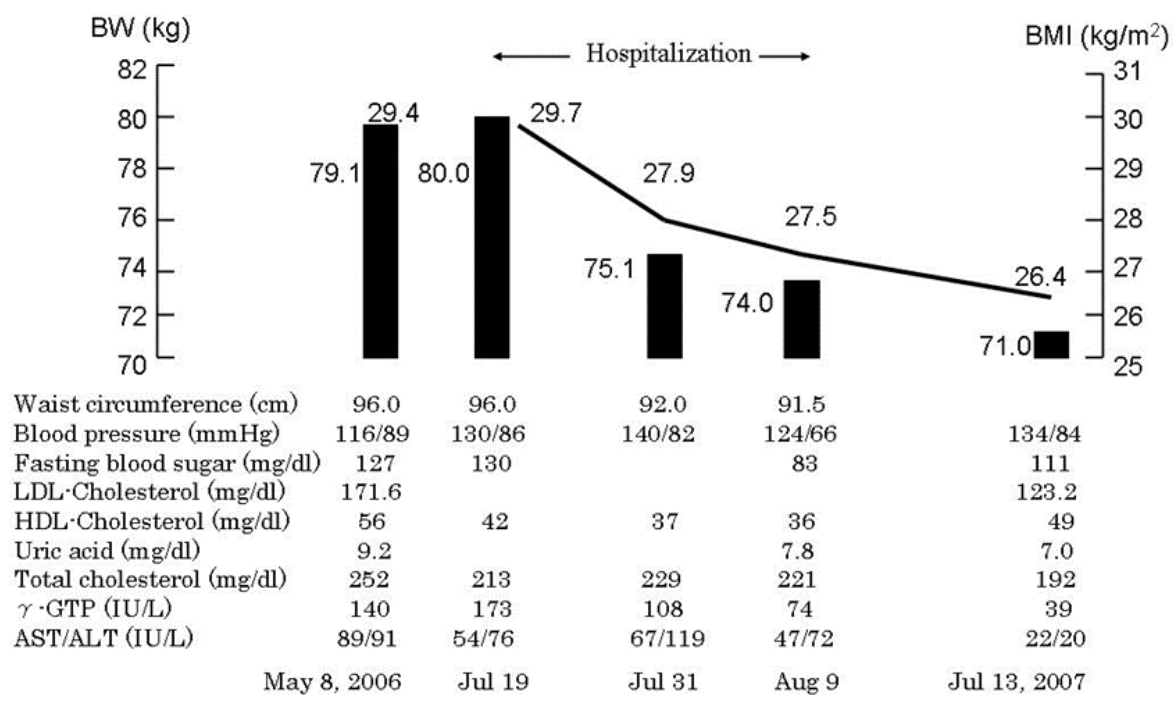

Figure 1 Clinical course of Case 1. May 8, 2006 and July 13, 2007 are the dates of health screenings. BW, body weight; BMI, body mass index.

Bodyweight and several laboratory findings on the admission were similar to the health screening two months prior (Figure 1). VFA and SFA were $97.0 \mathrm{~cm}^{2}$ and $202.4 \mathrm{~cm}^{2}$, respectively (Figure 2a, 2b) $[6]$. 

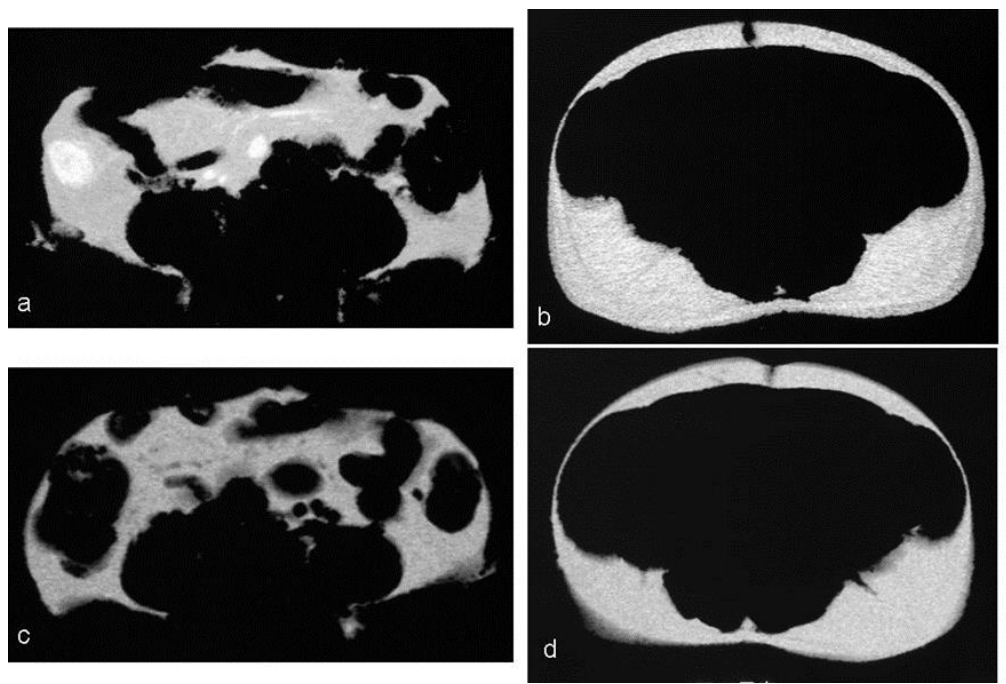

Figure 2 Computed tomogram at the umbilical level showing visceral (a and c) and subcutaneous ( $b$ and d) fat areas in Case 1 [6]. Panels $a$ and $b$ were obtained at admission (July 20, 2006), and Panels $c$ and $d$ were obtained two weeks later (August 2, 2006). a, $97.0 \mathrm{~cm}^{2} ; \mathrm{b}, 202.4 \mathrm{~cm}^{2} ; \mathrm{c}, 90.3 \mathrm{~cm}^{2} ; \mathrm{d}, 177.4 \mathrm{~cm}^{2}$.

As for common health practices [18], he stopped smoking two years previously, practiced calisthenics in the morning, drank Japanese sake $(722 \mathrm{~mL} /$ day $)$, slept for 5 to $8 \mathrm{~h}$ at night, ate breakfast every morning, and ate sweets between meals. The PBDS before the admission was 13 (Table 2).

\subsubsection{Clinical Course}

He received $1400 \mathrm{kcal} / \mathrm{day}$ ( $23.6 \mathrm{kcal}$ per $\mathrm{kg}$ of standard bodyweight) and ate all of the meals. No medication was prescribed for hyperuricemia. A weight loss of $4.9 \mathrm{~kg}$ ( $6.1 \%$ of body weight) was achieved two weeks after the treatment. Both VFA and SFA decreased to $90.3 \mathrm{~cm}^{2}$ and $177.4 \mathrm{~cm}^{2}$, respectively (Figure $2 \mathrm{c}, 2 \mathrm{~d}$; Table 1). Although two weeks of hospitalization were planned initially, he extended the hospitalization for one more week due to the treatment's effectiveness (Figure 1). At discharge in the mid of August, his BMI, body weight, fasting blood sugar, and blood pressure were $27.5 \mathrm{~kg} / \mathrm{m}^{2}, 74.0 \mathrm{~kg}, 83 \mathrm{mg} / \mathrm{dL}$, and 124/66 mmHg, respectively (Figure 1).

He had an annual health screening in the mid of July 2007, nearly one year after the hospitalization. His weight reduced further to $71.0 \mathrm{~kg}$ (BMI $26.4 \mathrm{~kg} / \mathrm{m}^{2}$ ). Low density lipoprotein $(\mathrm{LDL})$ cholesterol $(123.2 \mathrm{mg} / \mathrm{dL})$ and total cholesterol $(192 \mathrm{mg} / \mathrm{dL})$ were normalized (Figure 1$)$. Uric acid $(7.0 \mathrm{mg} / \mathrm{dL})$, AST $(22 \mathrm{U} / \mathrm{L})$, ALT $(20 \mathrm{U} / \mathrm{L})$, and $\mathrm{\gamma}$-GTP $(39 \mathrm{U} / \mathrm{L})$ were also normalized. However, fasting blood sugar $(111 \mathrm{mg} / \mathrm{dL})$ and blood pressure $(134 / 84 \mathrm{mmHg})$ were unchanged.

\subsection{Case 2}

A 61-year-old man was referred to our division for weight loss. He was on an anti-hypertensive drug. His BMI exceeded $30.0\left(31.2 \mathrm{~kg} / \mathrm{m}^{2}\right)$, and fasting blood sugar $(111 \mathrm{mg} / \mathrm{dL})$ was slightly over the reference range. VFA and SFA were $94.7 \mathrm{~cm}^{2}$ and $222.2 \mathrm{~cm}^{2}$, respectively (Table 1). He drank alcohol every night, and his PBDS was 12 (Table 2). 


\subsubsection{Clinical Course}

He received $1400 \mathrm{kcal} / \mathrm{day}$ ( $25.3 \mathrm{kcal}$ per $\mathrm{kg}$ of standard body weight). A weight loss of $5.2 \mathrm{~kg}(6.6 \%$ of body weight) was achieved two weeks after the treatment. Both VFA and SFA decreased to 77.0 $\mathrm{cm}^{2}$ and $174.4 \mathrm{~cm}^{2}$, respectively. Fasting blood sugar decreased to $105 \mathrm{mg} / \mathrm{dL}$, within the reference range (Table 1). He returned to the referring doctor after discharge.

\subsection{Case 3}

A 55-year-old man visited our division to lose weight before his retirement. He was on medications for hypertension and dyslipidemia. VFA was $128 \mathrm{~cm}^{2}$, and total cholesterol was 260 $\mathrm{mg} / \mathrm{dL}$ (Table 1). He drank alcohol every night, and his PBDS was 0 (PBDS+ 21 and PBDS- 21) (Table 2).

\subsubsection{Clinical course}

Initially, he received $1400 \mathrm{kcal} / \mathrm{day}$ ( $21.5 \mathrm{kcal}$ per $\mathrm{kg}$ of standard body weight), which was decreased five days later to $1100 \mathrm{kcal} /$ day $(16.9 \mathrm{kcal}$ per $\mathrm{kg}$ of standard bodyweight) because there was no decrease in body weight. Two weeks after hospitalization, a weight loss of $2.3 \mathrm{~kg}(2.9 \%$ of body weight) was achieved. VFA decreased to $103 \mathrm{~cm}^{2}$, and total cholesterol decreased to 193 $\mathrm{mg} / \mathrm{dL}$, within the reference range (Table 1 ). Three years after the hospitalization, his bodyweight steadily increased to $82.8 \mathrm{~kg}$.

\section{Discussion}

Abdominal obesity, insulin resistance, elevated blood pressure, and dyslipidemia are important risk factors for atherosclerotic cardiovascular disease, which prompted the concept of metabolic syndrome [21, 22]. Metabolic syndrome is accompanied by a two-fold increase in coronary heart disease risk and a five-fold increase in type 2 diabetes [21-23]. In Japan, according to the National Study in 2018, metabolic syndrome constitutes around one-third of adult men (30.4\%) and onetenth of adult women (11.9\%) [24].

The management of metabolic syndrome is based on a patient's risk categories: low risk, moderate risk, moderately-high risk, high risk, and very-high risk [22]. Our patients did not develop coronary heart disease or diabetes and were non-smokers, which corresponds to moderate risk (Table 1). Therefore, lifestyle interventions without medication were applied to these patients [22]. Three items advocated for lifestyle interventions in metabolic syndrome are weight loss, increased physical activity, and atherogenic diet modification [22].

A slow reduction in baseline weight from 7 to $10 \%$ for the first year and further reduction to the desired weight is recommended [22]. A Japanese study showed significant health benefits with small amounts of weight loss [25]. Based on this observation, the Guidelines for the Management of Obesity Disease 2016 [26] recommended a minimum of 3\% weight reduction in Japan. Cases 1 and 2 achieved a weight loss of more than 3\%, and Case 3 achieved 2.9\% (nearly 3\%) during educational hospitalization. Therefore, two weeks of educational hospitalization are sufficient. Although there was weight gain after three years of hospitalization in Case 3, no weight gain for nearly one year was observed in Case 1 (Figure 1). 
PBD as a healthy diet is recommended to prevent common chronic diseases and cancer [1, 27, 28]. About $2.9 \%$ saturated fat of total calories, $144.4 \mathrm{mg} / 1400 \mathrm{kcal}$ dietary cholesterol, and $2 / 1$ polyunsaturated/saturated fatty acid ratio in our PBD satisfy recommendations against an atherogenic diet [22]. Our PBD can be modified in other countries and/or chronic diseases. Replacing an omnivorous westernized diet with a prudent (the healthy reference) diet has been recommended for decades $[1,2,4]$. Unfortunately, people do not follow the advice.

Comprehensive lifestyle changes are fundamental for treating chronic diseases $[29,30]$. However, changes in lifestyle, including dietary habits, are not straightforward [31]. The Japanese diet has become westernized and far from a PBD [32]. With increasing affluence, replacing our diet with a PBD is not easy. However, this can be achieved by a short period of educational hospitalization [33]. Hospitalization helps limit risk factors for obesity and our health, such as smoking, alcohol, sweets, and animal foods. At the same time, patients benefit from healthy foods, outdoor exercise, and a regular daily rhythm. In our IBD patients, experiencing the PBD during hospitalization helped in their long-term adherence to the PBD and enhanced self-management skills, resulting in suppressing flare-ups [11, 33, 34]. Widespread use of educational hospitalization for obesity and other chronic diseases could contribute to personal benefits to the patients themselves and health-care cost savings.

Although several weight-loss diets have been reported [35, 36], PBD resulting in swift weight loss through educational hospitalization can be included in the list of weight-loss diets.

\section{Conclusions}

Restriction in total calories in the form of PBD and a 1-hour walk through educational hospitalization effectively reduced body weight and improved other obesity-related parameters associated with metabolic syndrome. Thus, PBD can be an effective weight loss diet.

\section{Acknowledgments}

The authors thank Mrs. Miki Yamada and Mrs. Koko Yamada, registered dietitians, and other staff of the dietary division of Nakadori General Hospital and Akita City Hospital for providing the semi-vegetarian diet.

\section{Author Contributions}

Study design and writing: Mitsuro Chiba. Acquisition, analysis, or interpretation of data: All authors. All authors approved the final version of the manuscript for submission.

\section{Competing Interests}

The authors have declared that no competing interests exist.

\section{References}

1. Willett $W$, Rockström J, Loken B, Springmann $M$, Lang $T$, Vermeulen $S$, et al. Food in the Anthropocene: The EAT-Lancet Commission on healthy diets from sustainable food systems. Lancet. 2019; 393; 447-492. 
2. Wolf ID, Peterkin BB. Dietary guidelines: The USDA perspective. Food Technol. 1984; 38: 80-86.

3. Rizzello F, Spisni E, Giovanardi E, Imbesi V, Salice M, Alvisi P, et al. Implications of the westernized diet in the onset and progression of IBD. Nutrients. 2019; 11: 1033.

4. Popkin BM. The nutrition transition in low-income countries: An emerging crisis. Nutr Rev. 1994; 52: 285-298.

5. Drewnowski A, Popkin BM. The nutrition transition: New trends in the global diet. Nutr Rev. 1997; 55: 31-43.

6. Japan Society for the Study of Obesity, Examination Committee of Criteria for 'Obesity Disease' in Japan. New criteria for 'obesity disease' in Japan. Circ J. 2002; 66: 987-992.

7. Outcomes of National Health and Nutritional Study in 2019. The Ministry of Health [Internet]. Labor and Welfare; Japan. Available from: http://www.mhlw.go.jp/content/10900000/000687163.pdf

8. Wu GD, Chen J, Hoffmann C, Bittinger K, Chen YY, Keilbaugh SA, et al. Linking long-term dietary patterns with gut microbial enterotypes. Science. 2011; 334: 105-108.

9. David LA, Maurice CF, Carmody RN, Gootenberg DB, Button JE, Wolfe BE, et al. Diet rapidly and reproducibly alters the human gut microbiome. Nature. 2014; 505: 559-563.

10. Kaplan GG, Ng SC. Understanding and preventing the global increase of inflammatory bowel disease. Gastroenterology. 2017; 152: 313-321.

11. Chiba M, Abe T, Tsuda H, Sugawara T, Tsuda S, Tozawa $H$, et al. Lifestyle-related disease in Crohn's disease: Relapse prevention by a semi-vegetarian diet. World J Gastroenterol. 2010; 16: 2484-2495.

12. Chiba M, Nakane K, Komatsu M. Westernized diet is the most ubiquitous environmental factor in inflammatory bowel disease. Perm J. 2019; 23: 18-107.

13. Chiba M, Ishii $\mathrm{H}$, Komatsu M. Recommendation of plant-based diet for inflammatory bowel disease. Transl Pediatr. 2019; 8: 23-27.

14. Marchesi JR, Adams DH, Fava F, Hermes GD, Hirschfield GM, Hold G, et al. The gut microbiota and host health: A new clinical frontier. Gut. 2016; 65: 330-339.

15. Pttayanon R, Lau JT, Leontiadis GI, Tse F, Yuan Y, Surette M, et al. Differences in gut microbiota in patients with vs without inflammatory bowel disease: A systematic review. Gastroenterology. 2020; 158: 930-946.

16. Morgan XC, Tickle TL, Sokol H, Gevers D, Devaney KL, Ward DV, et al. Dysfunction of the intestinal microbiome in inflammatory bowel disease and treatment. Genome Biol. 2012; 13: R79.

17. Chiba M, Nakane $K$, Abe $H$, Komatsu M, Tozawa $H$. Onset of ulcerative colitis in a patient with nonalcoholic fatty liver disease (NAFLD): Dramatic effect of plant-based diet for NAFLD. Inflamm Bowel Dis. 2019; 25: e146-e147.

18. Breslow L, Enstrom JE. Persistence of health habits and their relationship to mortality. Prev Med. 1980; 9: 469-483.

19. Dietary Reference Intakes for Japanese [Internet]. Ministry of Health, Labor, and Welfare; Japan. Available from: http://www.mhlw.go.jp/houdou/2004/11/d1/h1122-2b.pdf

20. Chiba M, Nakane K, Takayama Y, Sugawara K, Ohno H, Ishii H, et al. Development and application of a plant-based diet scoring system for Japanese patients with inflammatory bowel disease. Perm J. 2016; 20: 16-19. 
21. Matsuzawa Y. Committee to evaluate diagnostic standards for metabolic syndrome: Definition and the diagnostic standard for metabolic syndrome. Nihon Naika Gakkai Zasshi (Journal of the Japanese Society of Internal Medicine). 2005; 94: 794-809.

22. Grundy SM, Cleeman JI, Daniels SR, Donato KA, Eckel RH, Franklin BA, et al. Diagnosis and management of the metabolic syndrome. An American Heart Association/National Heart, Lung, and Blood Institute scientific statement. Executive summary. Cardiol Rev. 2005; 13: 322-327.

23. Iso $\mathrm{H}$, Sato S, Kitamura A, Imano H, Kiyama M, Yamagishi $\mathrm{K}$, et al. Metabolic syndrome and the risk of ischemic heart disease and stroke among Japanese men and women. Stroke. 2007; 38: 1744-1751.

24. Outcomes of National Health and Nutritional Study in 2018 [Internet]. The Ministry of Health, Labor and Welfare; Japan. Available from: https://www.mhlw.go.jp/content/000615344.pdf

25. Muramoto A, Matsushita M, Kato A, Yamamoto N, Koike G, Nakamura M, et al. Three percent weight reduction is the minimum requirement to improve health hazards in obese and overweight people in Japan. Obes Res Clin Pract. 2014; 8: e466-e475.

26. Miyazaki S, Mori M, Ogawa Y. Guidelines for the management of obesity disease 2016. Nihon Naika Gakkai Zasshi (Journal of the Japanese Society of Internal Medicine). 2018; 107: 262-268.

27. The 2015 Dietary Guidelines for Americans. US Department of Health and Human Services: Washington; 2015.

28. Grant JD. Time for change. Benefits of a plant-based diet. Can Fam Physician. 2017; 63: 744746.

29. Ornish D, Scherwitz LW, Billings JH, Gould KL, Merritt TA, Sparler S, et al. Intensive lifestyle changes for reversal of coronary heart disease. JAMA. 1998; 280: 2001-2007.

30. Knowler WC, Barrett-Connor E, Fowler SE, Hamman RF, Lachin JM, Walker EA, et al. Reduction in the incidence of type 2 diabetes with lifestyle intervention or metformin. N Engl J Med. 2002; 346: 393-403.

31. Desroches S, Lapointe A, Ratter S, Gravel K, Legatee F, Turcotte S. Interventions to enhance adherence to dietary advice for preventing and managing chronic diseases in adults. Cochrane Database Syst Rev. 2013; 28: CD008722.

32. Tada N, Maruyama C, Koba S, Tanaka H, Birou S, Teramoto T, et al. Japanese dietary lifestyle and cardiovascular disease. J Atheroscler Thromb. 2011; 18: 723-734.

33. Chiba M, Nakane K, Tsuji T, Tsuda S, Ishii H, Ohno H, et al. Relapse prevention in ulcerative colitis by plant-based diet through educational hospitalization: A single-group trial. Perm J. 2018; 22: 17-167.

34. Chiba M, Nakane K, Tsuji T, Tsuda S, Ishii H, Ohno H, et al. Relapse prevention by plant-based diet incorporated into induction therapy for ulcerative colitis: A single group trial. Perm J. 2019; 23: $18-220$.

35. Shai I, Schwarzfuchs D, Henkin Y, Shahar DR, Witkow S, Greenberg I, et al. Weight loss with a low-carbohydrate, Mediterranean, or low-fat diet. N Engl J Med. 2008; 359: 229-241.

36. Atallah R, Filion KB, Wakil SM, Genest J, Joseph L, Poirier P, et al. Long-term effects of 4 popular diets on weight loss and cardiovascular risk factors: A systematic review of randomized controlled trials. Circ Cardiovasc Qual Outcomes. 2014; 7: 815-827. 
OBM Integrative and Complementary Medicine 2021; 6(1), doi:10.21926/obm.icm.2101006

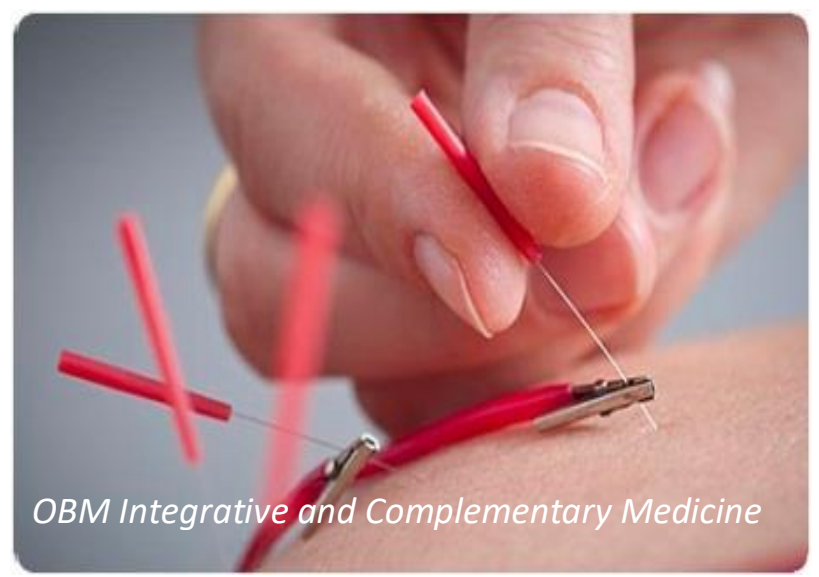

Enjoy $O B M$ Integrative and Complementary Medicine by:

1. Submitting a manuscript

2. Joining in volunteer reviewer bank

3. Joining Editorial Board

4. Guest editing a special issue

For more details, please visit:

http://www.lidsen.com/journals/icm 